https://doi.org/10.48009/4_iis_2020_73-80

Issues in Information Systems

Volume 21, Issue 4, pp. 73-80, 2020

\title{
IT GRADUATE STUDENTS’ PERCEPTIONS OF EMBEDDED LIBRARIANS
}

\author{
S.C. Spangler, Middle Georgia State University, scott.spangler@mga.edu
}

\begin{abstract}
The purpose of this qualitative study is to assess graduate IT students' perception of an embedded librarian in an online learning management system. The pilot research data were collected through a random sample $(n=13)$ of volunteer graduate student participants after two-course completions. The researcher constructs a post-course focus group interview session to seek congruent literature themes: perception of comfort in experience, the perception of assignment confidence, and enhanced perception in research abilities similar to past literature studies. To construct validity, the data were contextually constructed and assessed by participants and then spiraled down using Quirkos qualitative analysis software. Later, the findings are discussed to form a grounded theory. The pilot study concurs with the literature's three main constructs, recognizes additional themes, and constructs negative themes of concern. Finally, the study makes recommendations for furthering the research and acknowledges its limitations.
\end{abstract}

Keywords: embedded librarian, course-integrated instruction, graduate instruction, online instruction.

\section{INTRODUCTION}

Technology has long been a method to strike large disruptions in paradigms. Until recently, online teaching in higher education lagged faculty and librarian participation largely across universities and colleges in the United States. With the onset of the global Covid19 Pandemic, universities and colleges have never been faced with finding quick distancelearning methods to service students' requirements until now for sustainability. One important requirement for sustainability consists of constant contact in the library science domains. Additionally, until recently, librarians have traditionally been sheltered in quiet halls filled with books and shushed students. The simplistic face-to-face engagement process was simple. Students came to the libraries seeking information and help finding research to cite. Or to help foster success, librarians-with the invitation of faculty members-first engaged students in their face-to-face classrooms as a method to encourage library patronage. However, the onset pandemic and technology has changed the way students gather information today (2020). The pandemic situation-whereby students are studying and forced to stay inside their homes-creates an avenue for librarians to revitalize their outreach techniques and refocus the way libraries manage information distribution to students. To counterbalance these changes, librarians are meeting students' demands through online course embedment. Much like the media embeds journalists in war torn arenas, universities today are striking a new foxhole in academic paradigm to reach distance learners and fulfill an educational gap. This paper will seek to understand how graduate students perceive the new paradoxical splinter in library sciences and online education.

\section{Embedded Librarians}

\section{LITERATURE REVIEW}

Faculty have long invited industry officials into courses as guest speakers, mentors, liaisons, or course partnerships to foster organizational relationships (Mathew and Schroeder, 2006; Stewart, 2007; Bozeman and Owens, 2008; Chesnut et al., 2009). The term embedded itself originates from the journalistic correspondent act where reporters are deep-seated in combat zones with troops (Kesselman \& Watstein, 2009). In this embedded case, the librarian becomes an associate instructor for students and faculty members (Dewey, 2004, p. 5). The quasi instructor librarians insert themselves virtually into course shells as mentors or aids. Additionally, the embedded librarians aid faculty by creating virtual study tools (Edwards, Kumar, \& Ochoa, 2010, p. 273).

Researchers have uncovered common functions embedded librarians carry out when providing support in asynchrony situations beyond common librarian research assistance. Embedded librarians have multiple levels of engagement including simplistic search for research help, to course specific research tools and tutorial designs (Allen, 2017). Scholars suggest their online roles are extending into monitoring discussions for quality assurance, designing deeper learning modules and tutorials to assist faculty for reaching learning outcomes, and asserting ethics and copyright information into online courses (Abrizah, 2016; Allen, 2017; and Alverson et al., 2019). Distance education platforms emphasize the 


\section{Issues in Information Systems \\ Volume 21, Issue 4, pp. 73-80, 2020}

same learning outcomes as face-to-face courses but need literacy instruction and creation on a self-paced and methodology that allows revalidation methods for the learner. Hence, a predominate role embedded librarians carry is creating tutorials and learning modules that can be facilitated through online learning management systems. The online tutorials have been found to increase confidence, reduce anxiety, build perceptions of abilities while increasing and familiarity to library sciences offerings (Gorman \& Staley, 2018; and Spangler et al. 2020).

\section{Anxiety Reduction}

Students have long feared asking for help. Mellon's (1986) research constructed a culture of anxiety riddled students fear based from thoughts of inadequacy in mathematics. The fear-based anxiety students are overwhelmed by library science's vast repositories of knowledge furthering their regards of inadequacy and inefficiency. The inadequacy regards further student's anxiety and common overwhelming experiences that create a negative fostering of abilities with today's database structure of library science holdings (Psopelova et al. 2018). Research shadows effectiveness of embedded librarians into face-to-face offerings or telecommunication learning methods (Zhang, Watson and Banfield et al., 2007; Dugan, 2008; Hall, 2008; and Kesselman and Watstein, 2009). Zhang et al. (2007) discussed how early embedded faceto-face librarians increased information literacy through hands-on interaction. While computer-assisted library instruction research (Edwards, Kumar, \& Ochoa, 2010) uncovers a new and congruent effectiveness nature with the embedded librarians' presence. The virtualization of an embedded librarian into an online course's shell diminish geographical expanses, reduces the online instructional design limitations in resources and connectivity and collaboration (Edwards, et al., 2010; and Spangler, 2019).

To counter this anxiety, online embedded librarian's research tutorials have been created in areas of database searching constructions, citation clarity, and plagiarism reduction. Interestingly noted in Hoffman, (2011), the mere concept of services demonstrates a student anxiety reduction. Student who utilize the tutorials have been reported to reduce levels and created considerable levels of confidence in abilities Kumar \& Edwards, 2013; Paganelli \& Paganelli, 2017; and Spangler, 2019; Spangler et al. 2020). Spangler's (2019) researcher suggested students favored online librarian instruction, and students gained confidence from embedded librarians' aid in utilizing databases (Gorman \& Staley, 2018).

\section{Confidence and Abilities Increases}

Exposure to library sciences has long been understood to increase student retention, abilities, and confidence in coursework (Heathcock, 2011; Horn et al. 2013). The initial face-to-face instructional liaisonships have sprouted student perceptions of abilities (Horne et al., 2013), and the online embedded concepts of today's distance learning library science module concepts increase higher perceptions of confidence (Zhang et al. 2015). Xiao's (2010) research $(n=71)$ demonstrates positive growth in students' abilities from supplemental support (92\%). Additionally, students fostered greater ability in discovering specific course resources (90\%), an overall improved student research ability (83\%), and course reduction in citation errors or plagiarism. Additionally, Edwards' et al., (2010) research shows students gained an increase in self-efficacy and a greater overall confidence and comfortability in abilities. Students state the librarian's generate self-efficacy and a $16 \%$ increase in confidence in task completion, $23 \%$ increase in comfort with finding resources (p. 284). Library science instructional videos and tutorials have demonstrated a significant increase in student's abilities and overall increase in confidence boosts in pre-and post-tests by scholars (Edwards et al. 2013). The confidence in abilities and reduction of anxieties themes were uncovered in online embedded situations (Abrizah et al. 2016), along with students feeling an increase in interpersonal connections with librarians (Spangler, 2019), and a greater confidence level in their abilities to utilize library sciences (Spangler et al. 2020).

Kumar \& Edwards, (2013) confirmed a parent themes confidence building, collaboration and increased citation correctness, and plagiarism minimization. The body of literature shadows observations of anxiety and self-efficacy building. These observations where highlighted in Spangler's (2019) research on undergraduate students' perceptions of embedded librarians. Additionally, the gap distance between online and face-to-face librarian collaborations appears to diminish through streaming connectivity. As an example, Kumar \& Edwards, post-course survey, shadowed an increased confidence from the pre-course evaluations. The data constructs similar increases in students' citation knowledge and a noted anxiety reduction compliment. Similarly, confidence building, and self-efficacy assurances were noted in other observations (Blake et al., 2016; Horn, Maddox, Hagel, Currie, \& Owen, 2013; Matlin \& Lantzy, 2017; and PederseonSummey \& Akers-Kane, 2017; Pati \& Majhi, 2019; and Spangler, 2019). Matlin \& Lantzy, (2017) research observes 


\section{Issues in Information Systems \\ Volume 21, Issue 4, pp. 73-80, 2020}

superior assignment quality in students working with embedded librarians (pp. 102-104). Additionally, Soria, Fransen, \& Nackerud, (2017) constructed an afterthought suggesting students that had the opportunities work with embedded librarians were retained in the university longer and had higher graduation rates.

\section{METHODOLOGY}

The Middle Georgia State University Institutional Review Board (IRB) approved a qualitative pilot focus group study on graduate students' perceptions of embedded librarians in online courses. The methodology was adapted with permission from Edwards, Kumar, and Ochoa (2010) model to determine if graduate students' perceptions of online embedded librarians have congruent findings with the literature. The researchers' study seeks to understand if the literature's constructs are prevalent today: perception of comfort in experience, the perception of assignment confidence, and enhanced perception in research abilities. To analyze the data and construct a grounded model to study graduate students' perceptions, Lingelbach's (2018) grounded theory approach to interviewing participants has been adopted with permission.

\section{Procedure and Research Design}

The researcher fashioned a post-course focus group of volunteer participants $(n=13)$ upon IRB approval. Students were asked to participate in the study after passing their second course that had an embedded librarian entrenched in the course. The research shadowed Edwards, Kumar, and Ochoa (2010) model in construction to generate the questions and Lingelbach's (2018) data analyzation model to construct the data and its findings. Participants all signed confidentiality statements and were instructed on their ability to stop the research at any time. All participants accept one signed an IRB approved consent before starting the interviews. Data from the participant that failed to sign the consent form was destroyed prior to analysis.

Additionally, the researcher utilized Lingelbach's (2018) open-ended qualitative interview questions model to collect and validate the data. Furthermore, to ensure data validation and bias, the researcher collected data from the participants individually. To construct the data, the researcher asked participants to elaborate on the research questions' answers freely with no time barriers. Lingelbach's (2018) open-ended data collection method offered participants an opportunity to elaborate on their personal regards to the literature's themes instead of using "numerical data studies that would limit the study in strict boundaries or parameters" (Lingelbach, 2018, p. 33). Lingelbach's (2018) grounded theory model permitted the researcher to hypnotize an "analytical sense of meanings and actions" (p. 34). Lingelbach's (2018) transcription process, validation, and constant-comparative analysis method through Quirkos Software for coding was used to form a grounded theory and determine any outliers in the constructs. Additionally, the researcher followed Lingelbach’s (2018) method of providing the transcript to the participants to ensure data and findings validations.

\section{Sample}

The volunteer participants were 30\% female and 70\%, male. Participants were recruited through Edwards' et al. (2010) purposeful sampling method. A qualitative purposeful sampling method selects participants based on the ease of finding participants that meet the criteria (Lingelbach, 2018, p. 36). Similarly, to Edwards' et al. (2010), the research process exploited a post-course participant focus group interview session to validate the method further. All participants had complete access online to the embedded librarian and her educational tools through the Brightspace Learning Management System (LMS). All of the participants were students returning for a degree or in the workforce seeking an advancement. The majority of participants work full-time jobs $84 \%$, and $8 \%$ work part-time jobs, and $8 \%$ stated having no employment while in graduate school.

\section{Reliability and Validity}

To validate the data's credibility, authenticity, and accuracy, the research followed Lingelbach's (2018) triangulation methods. Similarly, the researcher utilized Quirkos software to organize the transcriptions, create Quirk (nodes) codes to discuss findings. The quirks (nodes) help visualize the data. Again, Lingelbach's (2018) methods, axial coding was next engaged to connect quirks (nodes) to understand groupable meanings. Finally, Spangler's (2019) selective coding and visualization process of the data constructs a model or theory. Participants constructed their own transcriptions to ensure credibility, authenticity, dependability. Additionally, the researcher discussed the findings with participants to ensure 


\section{Issues in Information Systems \\ Volume 21, Issue 4, pp. 73-80, 2020}

trustworthiness, validate the data analysis' themes, and create greater confidence. The researcher finalized the discussion by understanding the outlier conditions and presents a conclusion based on the to concur with the literature comparisons (Lingelbach, 2018, p. 39). The confidence in the data's formation and validity in transcription provides greater transferace in meaning. With permission from the scholars' literature, the researcher framed the research premises:

\section{Research questions}

RQ1: Does the presence of an online embedded librarian affect student's perceptions of course comfort?

RQ 2: Does the assistance of an online embedded librarian's and their tools affect student's perception of assignment confidence?

RQ 3: Does the presence of an online embedded librarian create an enhanced perception of abilities?

\section{RESULTS}

Overall, the data demonstrates some 26 Quirks or node themes in construction. The data constructs seven main areas of observation: helpfulness, confidence in abilities, helped reach goal, retention increases, increased retention perception, saved time researching, and negative impacts on success. Additionally, two outliers were discovered that didn't fold into the parent or child themes: reduction of stress, and the ability to help others from lessons.

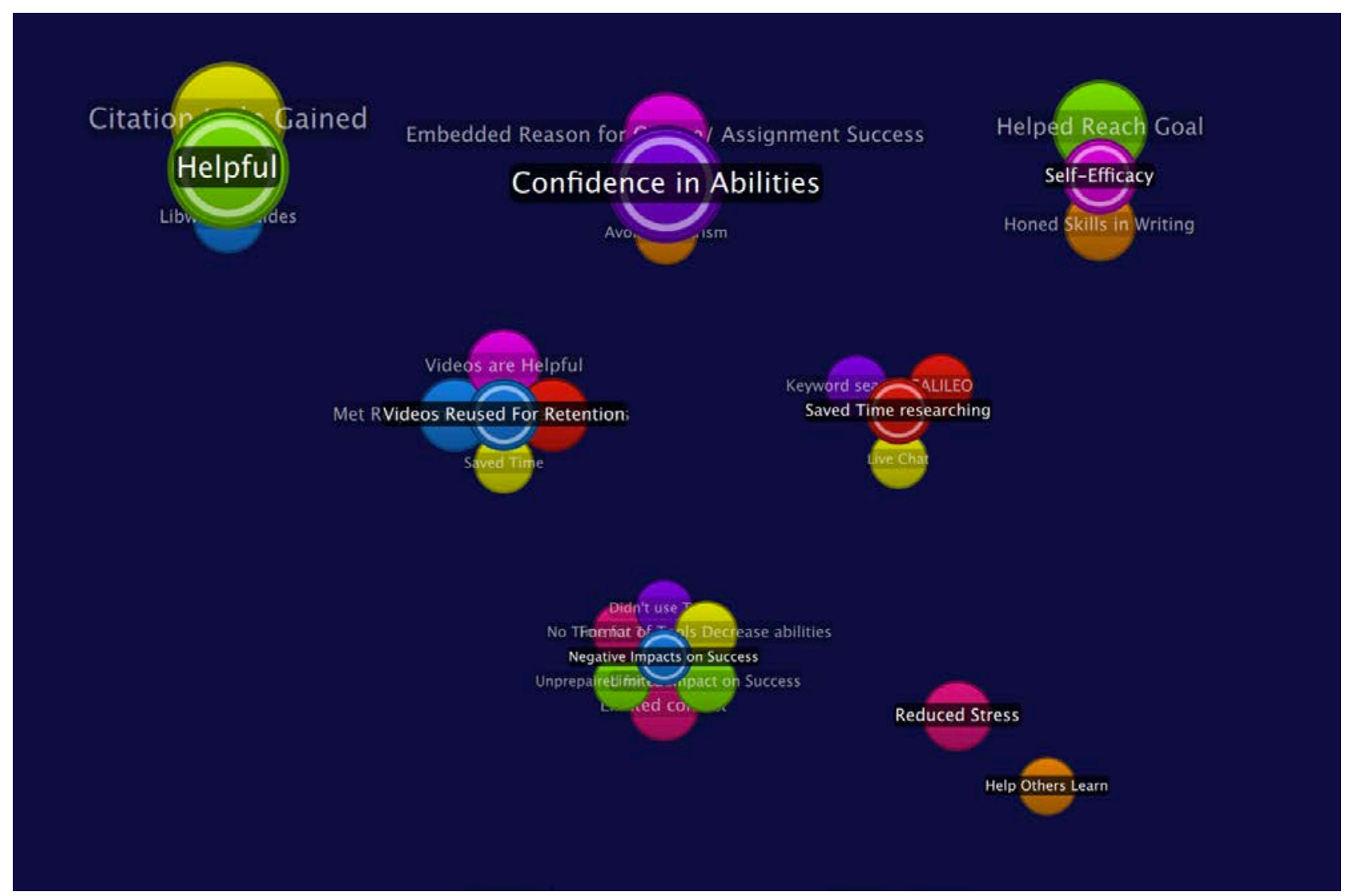

Figure 1. Visualization of the Data's Themes

The helpfulness category (Figure 1) observed some 40 quirk notations. It is impacted by two main child groups: citation help gained (33 quirks) and LibWizard tools help (9 quirks). The second parent theme of confidence in abilities observed some 36 Quirks and two child themes of confidence in assignment success (11 quirks) and avoidance of plagiarism (4 quirks). The helped reach goal parent theme uncovered 22 quirks and two child themes: self-efficacy (11 quirks) and 


\section{Issues in Information Systems \\ Volume 21, Issue 4, pp. 73-80, 2020}

honed skills in writing (9 quirks). The increased retention perception parent theme observed nearly equal values in its children of 10 quirks (videos are helpful, saved time in researching, met requirements with ease) and the librarian's tools are considered time saving additions (observing two quirks). The final positive theme saved time researching (6 quirks) observed three child themes: keyword searching clarity (4 quirks), Galileo understanding (4 quirks), and live session help ( 2 quirks). The two outliers reduced stress (6 quirks) and helped others learn (1 quirk) are interesting to note because of the significance to other studies findings.

Additionally, the data uncovered a final parent them that constructs a family of negative thoughts about embedded librarian's in the graduate mindset. The parent theme of negative impact on success found six child quirks. Each area or child theme summarizes the parent theme's construction. The child themes regard a view of limited personal contact with the embedded librarian: one student remarking didn't use any of the Libwizard tools; unprepared for researching information (4 quirks), the program had limited impact on success of personal goals (3 quirks); no time for the tools ( 2 quirks); the Libwizard tools' formats are distracting or cumbersome to use (4 quirks); and limited contact with embedded librarian throughout the courses (8 quirks).

\section{DISCUSSION}

The findings from the graduate students' perceptions on the embedded librarians finds similarities in the literature. Interestingly noted, the parent themes of helpfulness, confidence in abilities, helped reach goal are prevalent (Edwards, Kumar, \& Ochoa, 2010; Blake, Ballance, Davies, Gaines, Mears, Shipman, \& Burchfield, 2016; and Spangler, 2019). Other themes in Spangler's (2019) work shadowed greater impact like the notion of self-efficacy, anxiety and stress reduction, and plagiarism avoidance. These earlier findings may be constructed higher or with greater impact because of the nature of the maturing undergraduate students that lack research skills and knowledge about library sciences. However, it is interesting to note the increased acknowledgement towards retention success. In this scope, past literature dominates with regards to retention (Edwards, Kumar, \& Ochoa, 2010; Horn, Maddox, Hagel, Currie, \& Owen, 2013; Blake et al., 2016; Matlin \& Lantzy, 2017; and Pederseon-Summey \& Akers-Kane, 2017; Soria, Fransen, \& Nackerud, 2017). This notion was particularly expressed by Soria, Fransen, \& Nackerud, (2017) research that shadows a four-year success whereby students work with embedded librarians' one time in their years of study.

Nevertheless, this study can confirm RQ1: Does the presence of an online embedded librarian affect student's perceptions of course comfort? The data does construct enough positive quirks to proclaim graduate students do find the embedded librarians presence offering a guise of comfort. Nevertheless, the negative quirks discoveries, they do not overshadow the affirmative impact. Similarly, the paper confirms research RQ 2: Does the assistance of an online embedded librarian's and their tools affect student's perception of assignment confidence? Here quirk constructions in the confidence in abilities building and goal relevance are enough to affirm equality in the past literature's debates and current data's' constructs. Although it doesn't accept Spangler's (2019) construction of self-efficacy, it can observe a relative affirmative notation towards confidence building. And finally, the research asserts RQ 3: Does the presence of an online embedded librarian create an enhanced perception of abilities? Again, the same prior examined quirks and newfound data constructions of graduate students utilizing the embedded librarians' resources repeatedly for retention affirms the study's exploration question.

\section{CONCLUSION}

Understandably, the limitations in this study force the researcher to not generalize the context of the data to a wider audience. However, it can state a grander need for a larger quantitative study to understand deeper the impacts of the embedded librarians have on graduate students. One area of discovery in the undergraduate scholarship was the concept of self-efficacy (Spangler, 2019). Here, the research can't express the concept as its limitations failed to fully address the consideration. Hence, another study in a quantitative format my introduce deeper learning in the area. The researcher also contents a need for deeper research into how exactly graduates students find the presence of an embedded librarian comforting and having the ability to increase their comfort levels in online courses. This concept is in need of deeper exploration should be expressed with a psychological literature exploration that may help to describe its meanings. The paper's limitations in psychological literature also opens an area to explore about the perceptions of student's with visual representations of professors and librarians in online course shells. 


\section{Issues in Information Systems \\ Volume 21, Issue 4, pp. 73-80, 2020}

Additionally, to understand any of the found constructs like anxiety reduction or plagiarism reduction, the researcher proclaims a need to further the study on a large scale. The research also considers the limitation in geographical area a weakness. Again, a larger quantitative study that can cross examine international views of graduate students with domestic opinions and constructs could carry a different weight. Hence, the largest limitation is the scale of the population overall that restricts any generalization even in its limited population of survey.

However, the practical implications of this small pilot study do point out a need for embedded librarian programs in online courses. The need-now more than ever as society is currently in a pandemic situation whereby students are removed from any and all personal face-to-face contact with librarians-shadows the need for online course development and richness. Today, this study points out a shallow need for increases in library services to all students and reusable tutorials (LibWizard or video tutorials) for richer academic experiences. Nevertheless, the constraints of the small population, the study does outline a need for graduate students to have meaningful online library science help and for universities to foster programs for its global student bodies in the future.

\section{REFERENCES}

Abrizah, A., Inuwa, S., \& Afiqah-Izzati, N. (2016). Systematic literature review informing LIS professionals on embedding librarianship roles. The Journal of Academic Librarianship, 42(6), 636-643. https://doi.org/10.1016/j.acalib.2016.08.010

Allen, E. \& Seaman, J. (2017). Digital learning compass: Distance education enrollment report 2017. Babson Survey Research Group, e-Literate, and WCET. Retrieved from https://onlinelearningsurvey.com/reports/digtiallearningcompassenrollment2017.pdf

Allen, S. (2017). Mapping uncharted territory: Launching an online embedded librarian program. Journal of Library \& Information Services In Distance Learning, 11(1-2), 251-261. http://search.ebscohost.com/login.aspx?direct=true\&AuthType=ip,shib\&db=eric\&AN=EJ1133687\&site=edslive\&scope=site

Alverson, J. A., Schwartz, J., \& Shultz, S. (2019). Authentic assessment of student learning in an online class:Implications for embedded practice. College \& Research Libraries, 80(1), 32-43. Retrieved from http://search.ebscohost.com/login.aspx?direct=true\&AuthType=ip,shib\&db=lls\&AN=134257760\&site=edslive\&scope=site

Blake, L., Ballance, D., Davies, K., Gaines, J., Mears, K., Shipman, P., ... Burchfield, V. (2016). Patron perception and utilization of an embedded librarian. Journal of Medical Library Association, 104(3), 226-230.

Bowles-Terry, M. (2012). Library instruction and academic success: A mixed-methods assessment of a library instruction program. Evidence Based Library and Information Practice, 7(1), 82-95. https://doi.org/10.18438/B8PS4D

Chesnut, M. T., Henderson, S. M., Schlipp, J., \& Zai, R. (2009). Value-added library resources \& services through blackboard. Kentucky Libraries, 73(1), 6-12.

Ciccone, A., \& Hounslow, L. (2019). Re-envisioning the role of academic librarians for the digital learning environment: The case of UniSA Online. Journal of University Teaching and Learning Practice, 16(1). Retrieved from http://search.ebscohost.com/login.aspx?direct=true\&AuthType=ip,shib\&db=eric\&AN=EJ1213958\&site=eds -live\&scope=site

Clark, S., \& Chinburg, S. (2010). Research performance in undergraduates receiving face to face versus online library instructions: A citation analysis. Journal of Library Administration, 50, 530-542.

Dahlstrom, E., \& Bichsel, J. (2014). ECAR study of undergraduate students and information technology. ECAR: Research Report. Louisville, CO. Retrieved from http://www.educause.edu/ecar 
Dewey, B. I. (2004). The embedded librarian: Strategic campus collaboration. Resource Sharing and Information Networks, 17(1), 5-17. https://doi.org/10.1300/J121v17n01_02

Dugan, M. (2008). Embedded Librarians in an ag econ class: Transcending the traditional. Journal of Agricultural \& Food Information, 9(4), 310-309.

Edwards, M., Kumar, S., \& Ochoa, M. (2010). Assessing the value of embedded librarians in an online graduate educational technology course. Public Services Quartley, 6, 271-291.

Galanek, J. D., Gierdowski D. C., \& Brooks D. C., (2018) ECAR study of undergraduate students and information technology, 2018. ECAR: Research Report. Louisville, CO. Retrieved from https://ibrary.educause.edu/ /media/files/library/2018/10/studentitstudy2018.pdf?la=en

Gorman, E. F., \& Staley, C. (2018). Mortal or Moodle? A comparison of in-person vs. online information literacy instruction. Journal of Library \& Information Services in Distance Learning, 12(3-4), 219-236. Retrieved from http://search.ebscohost.com/login.aspx?direct=true\&AuthType=ip,shib\&db=eric\&AN=EJ1205498\&site=ed s-live\&scope $=$ site

Heathcock, K. (2015). Embedded librarians: Just-in-time or just-in-case? a research study. Journal of Library \& Information Services In Distance Learning, 9(1-2), 1-16. Retrieved from http://search.ebscohost.com/login.aspx?direct=true\&AuthType=ip,shib\&db=eric\&AN=EJ1058374\&site=ed s-live\&scope=site

Hall, R. A. (2008). The "embedded" librarian in a freshman speech class. College and Research Libraries News, 69(1), 28-30.

Horn, A., Maddox, A., Hagel, P., Currie, M., \& Owen, S. (2013). Embedded librarian services: Beyond chance encounters for students from low SES Backgrounds. Australian Academic \& Research Libraries, 44(4), 235-250.

Johnston, N. (2010). Is an online learning module an effective way to develop information literacy skills?

AustralianAcademic \& Research Libraries, 41(3), 207-218. https://doi.org/10.1080/00048623.2010.10721464

Kesselman, M. A., \& Watstein, S. B. (2009). Creating opportunities: Embedded librarians. Journal of Library Administration, 49(4), 383-400.

Kumar, S., \& Edwards, M. (2013). Information literacy skills and embedded librarianship in an online graduate program. Journal of Information Literacy, 7(1), 3-17. https://dx.doi.org/10.11645/7.1.1722

Lingelbach, K. (2018). Perceptions of female cybersecurity professionals toward factors that encourage females to the cybersecurity field (Doctoral dissertation). Nova Southeastern University, USA. (1056) Retrieved from NSUWorks, College of Engineering and Computing. Https://nsuworks.nova.edu/gscis_etd/1056.

Matthew, V., \& Schroeder, A. (2006). The embedded librarian program. EDUCAUSE Quarterly, 29(4), 61-65.

Matlin, T., \& Lantzy, T. (2017). Maintaining quality while expanding our reach: Using online information literacy tutorials in the sciences and health Sciences. Evidence Based Library and Information Practice, 12(3), 95-113.

Mayadas, F. (1997). Asynchronous learning networks: A Sloan Foundation perspective. Journal of Asynchronous Learning Networks, 1(1), 1-16.

Mellon, C. A. (1986). Library anxiety: A grounded theory and its development. College \& Research Libraries, 47(2), 160-2165. https://doi.org/10.5860/crl_47_02_160 
Meredith, W. \& Mussell, J. (2014). Amazed, appreciative, or ambivalent? Student and faculty perceptions of librarians embedded in online courses. Internet Reference Services Quarterly, 19(2), 89-112. https://doi.org/10.1080/10875301.2014.917756

Mestre, L. (2012). Designing effective library tutorials: A guide for accommodating multiple learning styles. Oxford, United Kingdom: Chandos Publishing.

Millsaps, J. (2013, April 16). Desire2Learn learning management system helps students manage college classes communications. University System of Georgia, USA. Retrieved from https://www.usg.edu/news/release/desire2learn_learning_management_system_helps_stu dents_manage_college_class

Paganelli, A., \& Paganelli, A. (2017). The online embedded personal librarian approach to providing reference services via a course management system. Journal of Electronic Resources Librarianship, 29(1), 54-60. https://doi.org/10.1080/1941126X.2017.1270105

Pederseon-Summey, T., \& Akers-Kane, C. (2017). Going where they are: Intentionally embedding librarians in course and measuring the impact on student learning. Journal of Library Information \& Information Services in Distance Learning, 11(1-2), 158-174. https://doi.org/10.1080/1533290x.2016.1229429

Pati, B. \& Majhi, S. (2019). Pragmatic implications of embedded librarianship in academics: A review of eminent literatures. Library Hi Tech News, (2), 11. Retrieved from https://doi.org/10.1108/LHTN-08-2018-0052

Pospelova, A., Tsurtsumia, R., \& Tsibulnikova, M. (2018). Embedded librarians as providers of knowledge services. Portal: Libraries \& the Academy, 18(4), 651-669. https://doi.org/10.1353/pla.2018.0039

Silke, K. J., Perrault, E. K., Ladenson, S., \& Nazione, S. A. (2015). The effectiveness of online versus in-person library instruction on finding empirical communication research. The Journal of Academic Librarianship, 41(2), 149-154. https://doi.org/10.1016/j.acalib.2014.12.007

Soria, K. M., Fransen, J., \& Nackerud, S., (2017). The impact of academic library resources on undergraduates' degree completion. College \& Research Libraries, 78(6), 812-823. https://doi.org/10.5860/crl.78.6.812

Spangler, S.C. (2019). Integrating information literacy in IT courses: Information technology students' perceptions of embedded librarians. Online Journal of Applied Knowledge Management, 7(2), 29-40.

Stewart, V. D. (2007). Embedded in the Blackboard jungle: The embedded librarian program at Pulaski Technical College. Arkansas Libraries, 64(3), 29-32.

Tumbleson, B. (2016). Collaborating in research: Embedded librarians in the learning management system. The Reference Librarian, 57(3), 224-234.

University System of Georgia. (2019, January 18). GeorgiaVIEW, University System of Georgia, USA. Retrieved from https://www.usg.edu/georgiaview/georgiaview

Xiao, J. (2010). Integrating information literacy into Blackboard: Librarian- faculty collaboration for successful student learning. Library Management, 31(8/9), 654-668. https://doi.org/10.1108/01435121011093423

Zhang, L., Watson, E. M., \& Banfield, L. (2007). The efficacy of computer-assisted instruction versus face-to-face instruction in academic libraries: A systematic review. Journal of Academic Librarianship, 33(4), 478484. 